to a chemist because it is more convenient, or because we do not stock the drug which is on the prescription.

I think that all comparisons between dispensing and prescribing costs are likely to be invalidated by the above points.

IAN COCKS

The Holts Health Centre

Newent, Gloucestershire GL18 1BA

\section{Community hospitals}

\section{$\mathrm{Sir}$,}

In his excellent editorial (June Journal, p.226) James Grant urges us to take community hospitals seriously and to see them as important ingredients of the health service of the future. We wholly support his aims but would like to report the results of a survey carried out in Southampton which highlights some of the difficulties in developing community hospitals.

In an undergraduate fourth-year project 145 acute medical admissions to Southampton general hospital were studied. Hospital doctors, nurses and referring general practitioners were interviewed to determine their views about the feasibility of general practitioners caring for these patients in an imaginary community hospital, whose facilities had been defined. For the 90 admission referred by general practitioners the hospital doctors thought that $35 \%$ could have been looked after by general practitioners, the nurses $31 \%$ and the referring general practitioners $48 \%$. However, consensus that the patient could be cared for by general practitioners in a community hospital was achieved in only $10 \%$ of cases. For the 55 admissions coming directly through casualty and the ambulance service the hospital doctors and nurses believed that a similar proportion, $31 \%$, could have been cared for by general practitioners.

Interviews were conducted with over half of the patients admitted. Most lived within five miles of the district hospital and most of their visitors found access quite straightforward. Few had previous experience of a community hospital, but at interview, when asked if they would have felt better or worse knowing that they were going to be looked after by their general practitioner, $26 \%$ of the patients said that they would have felt worse, $8 \%$ that they would have felt better and 55\% that they would have felt the same.

These results suggest that a substantial number of patients admitted to expensive district general hospitals could be cared for in general practitioner units, although the lack of consensus between health care professionals is concerning. Patients cared for in community hospitals tend to be ap- preciative and supportive of these facilities and it is likely that our results reflect lack of experience with this form of care. Nonetheless, patients' views about the place of care are important, not least because of the expectations they may reflect.

As James Grant points out, community hospitals have evolved in response to local needs and enthusiasms. Conversely, some attempts to get general practitioner units off the ground have foundered on the rocks of intertia and apathy, even before the government white paper ${ }^{1}$ and the new contract ${ }^{2}$ were published. Studies which will measure the cost effectiveness of community hospitals are urgently needed, as is the resolve not merely to sustain but to develop community hospitals as a precious and essential component of the National Health Service.

\section{DIARMUID KERRIN} ROGER JONES

Aldermoor Health Centre

Southampton SO1 6ST

\section{References}

1. Secretaries of State for Health, Wales, Northern Ireland and Scotland. Working for patients (Cm 555). London: HMSO, 1988.

2. Department of Health and the Welsh Office. General practice in the National Health Service. A new contract. London: Department of Health, 1989.

\section{Compulsory admission to hospital}

\section{Sir,}

Dr McGhee's letter on the compulsory admission to hospital of an alcoholic patient under the 1983 mental health act (July Journal, p.301) raises a number of issues which need to be given serious thought before this practice is repeated by other doctors.

In the compulsory admission of a patient to an approved institution the doctor takes a paternalistic role and the patient is deprived of one of the basic human rights, namely the right of self determination. The use of the act is therefore to be regarded with the utmost gravity, as the loss of personal liberty and the subsequent compulsory treatment profoundly affects the doctor-patient relationship. This change in the normal relationship persists until society deems that the patient is capable of making a rational and informed decision as to his or her choice of health care.

In alcoholism the patient is deciding that he will consume alcoholic beverages to a level that other members of society might believe, quite rightly, is irresponsible and to the detriment of his health. Being irresponsible is not in itself a varia- tion of human behaviour that allows the medical profession to intervene in a manner that deprives a patient of his liberty. To impose a medical model on a state that is more socially threatening than relevant to the spirit of the mental health act raises fundamental questions as to the role of the doctor in society.

The iniquitous practice of using psychiatry as a means of political or social control, which has been well documented in the eastern block countries, has been condemned by doctors. However well justified our concerns and fears for our patients, and despite the exhortation by friends and relatives that 'something must be done' if a patient does not satisfy the prevailing criteria for compulsory admission and treatment, we do not have the right to mould the acts of parliament to engineer social conformity, for to do so is not only unlawful but more pertinently unethical.

NiAll J. O’CONNELL

The Surgery

106 Crockhamwell Road

Woodley, Berkshire RG10 0LQ

\section{Needs of elderly people in residential homes}

Sir,

Dr Packham's paper (August Journal, p.335) raises an important issue, that lack of medical information hinders medical care, especially for the most disabled.

As a doctor who regularly visits residential homes to make assessments for attendance allowance I consider that access to patients' notes would be most helpful, particularly for obtaining the recent history prior to admission to the home or hospital, information which the staff often do not have. Patients might also benefit financially if earlier establishment of dependency leads to earlier payment of benefit.

The problem is presented as one of maintaining the confidentiality of patients' medical information and of respecting their autonomy. Confidentiality is not an absolute moral obligation and the General Medical Council's 'blue book' lists eight legitimate exceptions. A wide variety of health professionals, including administrative staff, have access to medical notes; allowing such access to residential nursing staff and visiting doctors would not therefore be a major departure.

The straightforward solution to respecting patients' autonomy would be to ask patients if they object to their notes being kept on the premises. The demented may lose a degree of autonomy but they 